\title{
Review on Restructuring of Malaysia Electricity Supply Industry
}

\author{
Zuraidah Ngadiron ${ }^{1, a}$, N.H Radzi ${ }^{1, b}$, Zaris Yassin $^{1}$, Izzati Amin ${ }^{1}$ \\ ${ }^{1}$ Faculty of Electrical and Electronic Engineering, Universiti Tun Hussein Onn Malaysia, Parit Raja, \\ Batu Pahat, 86400 Johor, Malaysia.

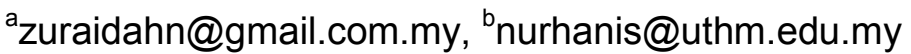

Key Words: Malaysia Electricity Supply Industry, Single Buyer, Pool Market, Hybrid Model

\begin{abstract}
The global trend in electricity market has put pressure for Malaysia to restructure industry to be more reliable, transparent, efficient and sustainable. Besides, centralized power purchasing units that exist within a vertically-integrated entity have been criticized for failure to provide a truly playing field for the player in the generation sector competing to sell power to the single buyer. The Malaysian Electricity Supply Industry (MESI) has gone through various stages of reform and has evolved from predominantly single entity to a multiplayer industry particularly in the generation sector. This literature review covers the evolution of MESI from the introducing of the Independent Power Producers (IPPs), issues surrounding and implementation of single buyer which had continued until now. The MESI reformed a single buyer functional structure and framework is also included. However, this model does not offer transparent competition. Thus, other alternative electricity market model, pool/hybrid market model could be applied in order to carry on the MESI previous plan towards restructuring. The significance and relevance of the pool market model and its advantages in the Malaysian context is also discussed.
\end{abstract}

\section{Introduction}

For many years MESI has remained a regulated monopoly. Today, with a major challenge to be more responsive to the needs of the people, keeping the price to be affordable and competitive, MESI made a progress in transforming the industry to be more transparent and efficient including the generation capacity. The restructuring of Electricity Supply Industry (ESI) had begun in early 20th centuries, since then, MESI has aimed to change its structure to a wholesale market model in 2005. Malaysian Government has addresses issues of energy production, distribution and consumption. Therefore, Tenaga Nasional Berhad (TNB) is committed to support the national green agenda and by applying sustainable, efficient operation and delivery green energy through the application of appropriate technologies and investments. In 1992, due to a nationwide power blackout, series interruptions and rationing, the government decided to introduce Independent Power Producers (IPP) in generation sector, in order to overcome the electricity shortage issues, enlarge energy reserve margin, and to introduce competition bidding among the generators [1]. Until now, the competition valid for generation sector only, while transmission and distribution sector remained fully control by TNB.

The future challenges may increase the cost of supply and subsidy, resulting in volatile fuel prices and IPP payments, as well as earnings below cost of capital. An alternative of electricity market model for MESI towards restructuring, pool/hybrid market model could be applied, in order to accommodate a fair competitive trading between power producers and to produce win-win situation to all involved parties, will illustrates guaranteed incomes for all IPPs. Therefore, this might influenced them to renegotiate the terms in the agreement.

Electricity Supply Industry Restructuring- The ESI revolution process includes competition, restructuring, privatization and regulation [2]. The objectives of these reforms are to enhance efficiency, to promote competition in order to lower costs, to increase customer choice, to assemble private investment and to merge public finances. The Malaysian Government identified the IPP 
model, whereby the capital-intensive development of new generation assets could be outsourced to the private sector, due to successful privatization agenda; this has become the initiative that would deliver the immediate national power security needed to maintain Gross Domestic Product (GDP) growth whilst not putting unnecessary pressure on TNB resources.

Evolution of Malaysia Electricity Supply Industry- The introduction of IPP had aided the TNB to overcome the electricity shortage issue and enlarge the electrical energy reserve margin. Since then, MESI had applied Single Buyer market model. Currently, there are 14 IPPs in the Peninsular of Malaysia, and the electrical energy is sold to the TNB on a fixed rate based on the Power Purchase Agreement (PPA). The PPA which last for 21 years is signed between the TNB and IPP for the purpose of market risks protection. The restructuring is supported with the existence of Energy Commission (EC) which is an electrical regulator in Malaysia [1].

The initial IPPs were given licenses to pursue the IPP model under PPAs, which govern the IPP how to construct, purchase and /or use of fuel, operate and sell energy produced. Under PPAs, TNB as the power of taker had agreed to pay for two types of payment; energy and capacity payment. The energy payment is done based on the electricity consumed by TNB, while the capacity payment is paid monthly regardless the usage of power generated by the IPPs, which provide extra revenue to the generator, to cover the capital and other fixed costs which are not covered by the energy price. Furthermore, it provides incentives for generators to stay online, at times when the system needs generation capacity. Thus, TNB has to bear the high expenses and suffered massive profit erosion. Moreover, TNB is also hit by the increasing of fuel cost. Meanwhile, the government is bearing the burden of rising cost due to the subsidies, but the IPPs are not sharing any of these burdens. When the demand getting slower, TNB could not sustain the capacity payment as it is fixed, accordingly electricity tariff have gone up for the end users, and consumers also faced risks as they depend on current market situation.

Single Buyer Market Model - The Grid Code associated with Grid System. The Grid Code is a set of technical regulation used by utility compare such as TNB and IPP in the Peninsular Malaysia that serve as the main guidelines in electricity supply operation, to ensure the electricity supply remain reliable. Figure 1 illustrates the Peninsular Malaysia industry structure in term of function as used in the Grid Code, where the single buyer located at the Grid Owner [3].

The single buyer model is relatively simple and quick to implement [9]. Basically, it provides for transition mechanism through all levels of competition; it handles the process of separating the purchasing function the grid function by establishing separate financial accounts and provides mechanism to supply franchise customers. However, the single buyer model has several disadvantages. This model does not provide any clear signals as to the value of improving the transmission network. Furthermore, the regulation is much more complicated to formulate and implement than in models with higher levels of competition. Most importantly, it is prone to corruption and imposes significant contingent liabilities on the government [4]. 

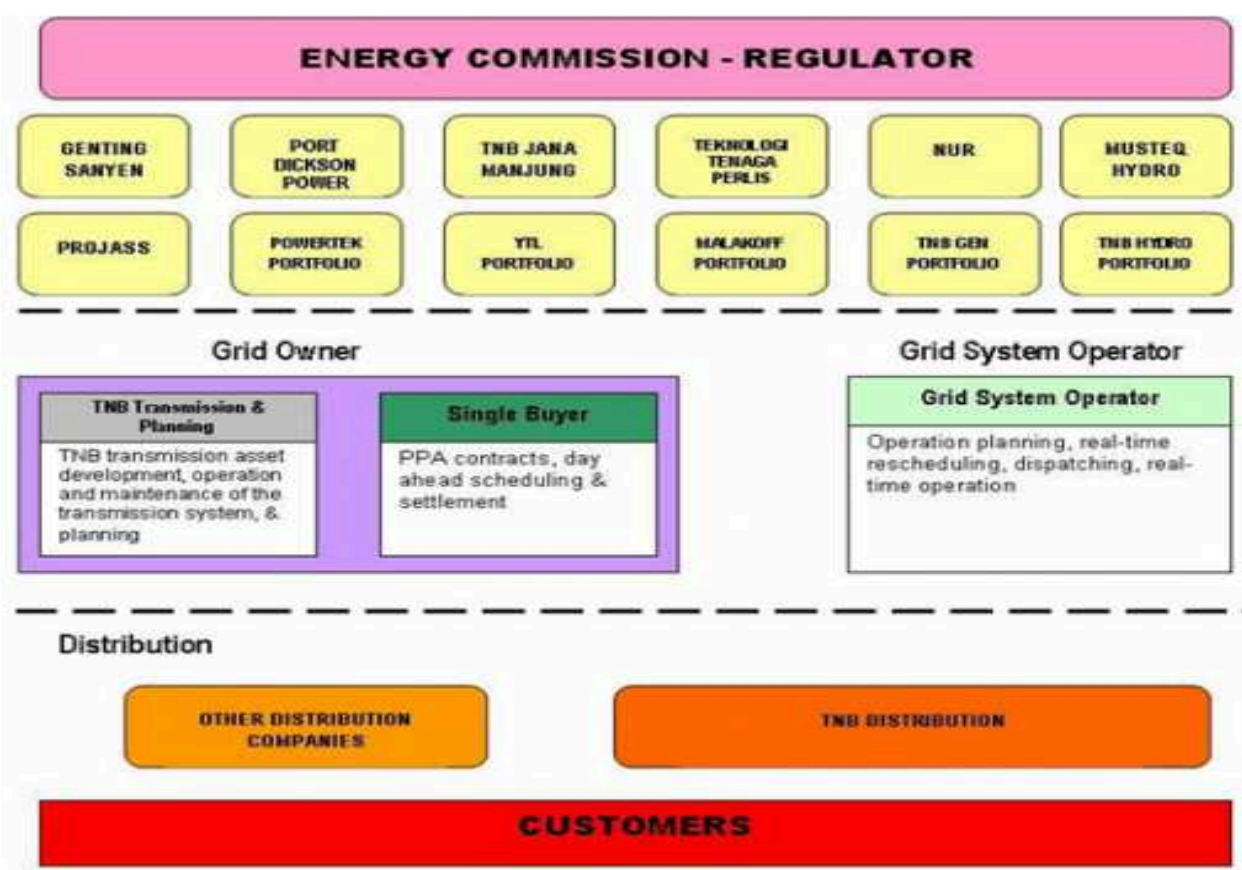

Figure 1: The Peninsular Malaysia Industry Structure

The evolution of MESI has leading to the formalization of the single buyer as shown at Figure 2 [4]. The MESI's reformed single buyer framework includes a new reporting structure and is ring-fenced to enhance transparency and accountability. The Single Buyer Rules and Codes of Conduct ensure the impartial and unbiased operationalization of the PPAs and further strengthen the roles of the regulator. Hence, to ensure greater transparency and efficiency in MESI, the single buyer function which was formerly embedded within TNB is now formalized through a series of structural changes, and rule settings under the new Managed Market Model (M3) structure as shown in Figure 2. The evolution of MESI towards the M3 model is another positive step towards reform.

Pool Market Model - The pool market model offers two types of market settlement which are single auction and double auction power pool. The pricing scheme which can be applied in the pool market model consists of two; i.e. uniform price which based on the system marginal price (SMP) and pay as bid which is based on the generator's energy bid price. In pool market model, all energy supply is controlled and coordinated by a single pool operator, who is normally known as independent market operator (IMO). There are two main sides of entities participating in the market, which are producers/supplier and customers/consumers. The IMO will consider the electricity bids and offers from these two entities to dispatch them in an economic manner depending on submitted bidding price and MW capacity [5]. The customers and suppliers do not interact to each other, but indirectly interact through the IMO. The IMO is responsible for both market settlement including scheduling and dispatch, also the transmission system management as well as transmission pricing and security aspects. 


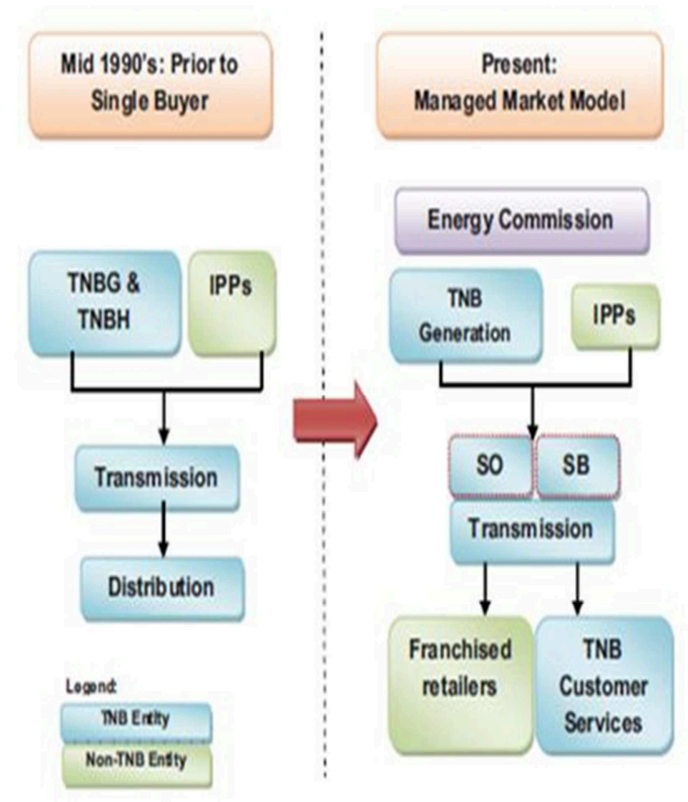

Figure 2: The single buyer model for electricity trading

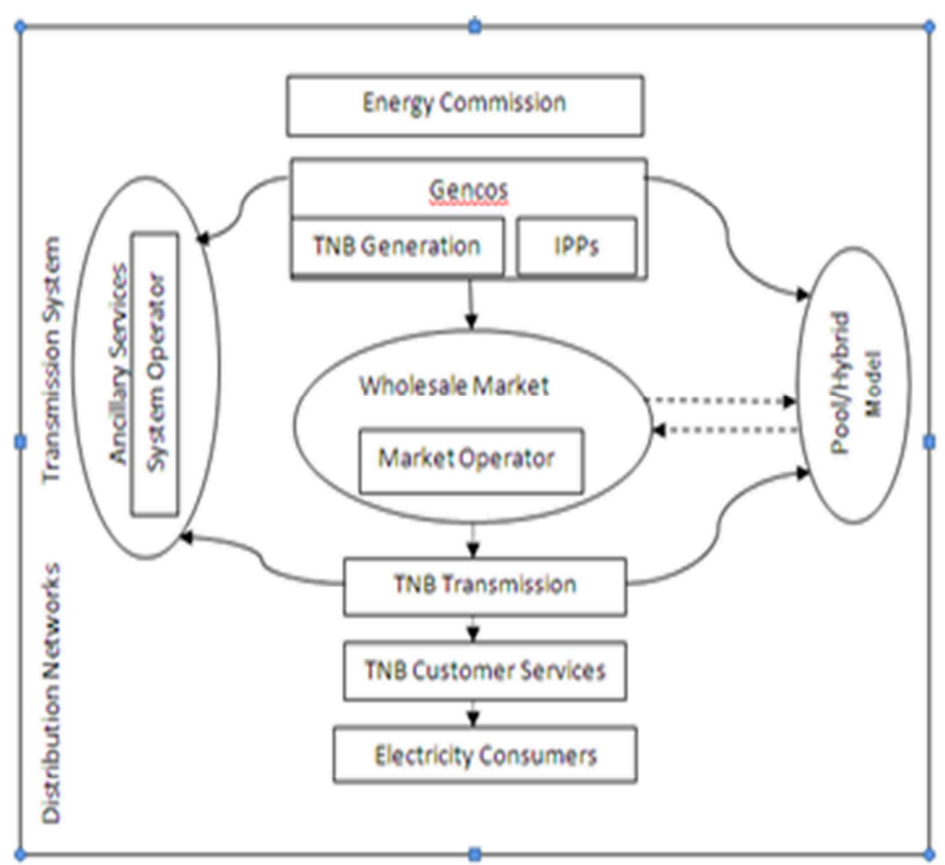

Figure 3: Diagram for Pool/ Hybrid Model in MESI

Hybrid Market Model - Figure 3 shows the diagram for pool/hybrid model in MESI. In this model, generating companies will sell all the electrical energy produced to the TNB. From the transmission to the distribution, the electricity will be re-priced and sell it to consumers. This wholesale market takes form of pool/hybrid market. In the hybrid market model, the load demand is divided into two parts; base load demand and peak load demand [6]. For the base load demand, the load is distributed to the generators based on the pro-rata basis, while there is no competition among generators and the generators will share this load proportional to their available capacity, i.e. generators with higher available capacity will have high percentage share of the base load demand. The remaining, peak load demand will be traded through competition of the energy bid price offered by each generator, whereas generator with a lower energy bid price has the priority to supply the remaining demand. The generator's payment for the base load demand would be based on the SMP, while for the remaining load demand would be based on their energy bid price The MW level of base load demand will be determined from the daily load curve.

Conclusion- Nowadays, the electricity tariff has gone up so much for the end-users. The single buyer model does not provide any competition due to the long-term agreement; that simplify the electricity trading under one company which is TNB transmission and distribution. Besides, the generators had gained the largest revenue due to the existence of both capacity and energy payment. These generators still can obtain revenue even without any contribution to supply the load demand. Thus, the IPPs need to renegotiate the terms in the PPA. Subsequently, the generator will get profit, distributor company pay appropriate amount and end-user enjoyed low tariff electricity.

The pool market model on the other hand, fully removed the capacity payment and has reduced the revenue some of the generators quite significantly. Nevertheless, by using hybrid model, all IPPs have equal opportunities to participate in the trading and receive some revenue from their contribution in base load demand. Therefore, the efficiency of the power producer and generation revenue is always kept at the adequate level. Finally, generators and consumer are able to experience a more competitive environment with efficient electricity supply. 


\section{References}

[1] Aifa Syireen Binti Arifin, Pool Based Electricity Market Design for Malaysia Electricity Supply Industry. Thesis Report. Faculty of Electrical Engineering, Universiti Teknologi Malaysia, 2008.

[2] Archana Singh and Prof. D.S. Chauhan, Electricity Sector Restructuring Experience of Different Countries, IJSER, ISSN 2229-5518, 2011.

[3] Peninsular Malaysia Electricity Supply Industry Outlook 2013 Published by Suruhanjaya Tenaga (Energy Commission).

[4] Noor Zafina Mohd Zamin, Nor Ziha Zainol Abidin and Joon B. Ibrahim, Single Buyer- A Step Forward in Malaysian Electricity Supply Industry Reform, IEEE, 978-1-4673-6349-5/13, 2013.

[5] Afrin Sultana, Pool versus Bilateral Markets: A Global Overview, University of Waterloo, Canada, $16^{\text {th }}$ August 2004.

[6] Hassan, Mohammad Yusri and Hussin, Faridah and Othman, Mohd. Fauzi, A study of electricity market models in the restructured electricity supplyindustry. Project Report. Faculty of Electrical Engineering, Skudai, Johor, VOT 78178, 2009.

[7] Steven Stoft, Power System Economics Designing Markets for Electricity, Wiley Interscience, 2003.

[8] An Introduction to Australia's National Electricity Market, ISBN 0-646-41233-7, 2010.

[9] CigdemCelik, Electric Power Market Models In Developing Countries, Istanbul Bilgi University,

[10] Daniel Kirschen and GorbanStrbac, Fundamental of Power System Economics, John Wiley \& Sons Ltd., 2004.

[11] Amir Khalid, "Effect of ambient temperature and oxygen concentration on ignition and combustion process of diesel spray", Asian Journal of Scientific Research, Volume 6, Issue 3, 2013, Pages 434-444,DOI: 10.3923/ajsr.2013.434-444.

[12] Amir Khalid, Keisuke Hayashi, Yoshiyuki Kidoguchi, TomoakiYatsufusa, "Effect of air entrainment and oxygen concentration on endothermic and heat recovery process of diesel ignition", (2011) SAE Technical Papers, DOI: 10.4271/2011-01-1834.

[13] T. J. Hammons, Status of Power Markets and Power Exchanges in Asia and Australia, Electricity Infrastructures in the Global Marketplace, (Ed.), ISBN: 978-953-307-155-8, 2011.

[14] Nurehan Othman, Mohammad Yusri Hassan, FaridahHussin, MdPauzi Abdullah, Generator Revenue Adequacy in the Competitive Electricity Markets : The case of Malaysia, International Journal of Integrated Engineering, Vol. 5 No. 3, p. 26-35, 2013. 